\title{
Study on The Reliability of Coke Research Establishment Micum 40 Formula to Predict Coke Micum 40 Strength at The Ajaokuta Steel Plant, Nigeria
}

\author{
${ }^{1}$ A.O. Adeleke, ${ }^{2}$ A.O. Olulana, ${ }^{2}$ A.B. Adahama, \\ ${ }^{2}$ R.S Makan, ${ }^{1}$ S.A. Ibitoye \\ ${ }^{1}$ Dept of Materials Science and Engineering, Obafemi Awolowo University, \\ Ile-Ife, Nigeria. \\ ${ }^{2}$ National Metallurgical Development Centre (NMDC), P.M.B. 2116, \\ Jos, Nigeria. \\ Corresponding Author: E-mail: aoadeleke2002@yahoo.com
}

\begin{abstract}
G-values of 0.97, 0.93, 0.94 and 1.01 were determined for Polish Bellview blend 1 (BV1), Polish Bellview blend 2 (BV2), Australian Agro-Allied blend (AA) and American Carbon Energy blend (CE), respectively. The coking duration of 18 hours, 17 hours, 16 hours and 22.5 hours, respectively were used to carbonize the coals each having volatiles $31.8 \%, 31.3 \%, 30.22 \%$, and $21.90 \%$, respectively. The Coke Research Establishment (CRE) formula predicted M40 micum strength of $77.98 \%, 77.12 \%, 77.55 \%$ and $92.05 \%$ for $B V 1, B V 2, A A$ and $C E$ blends, respectively. These predicted values were found to deviate from the experimentally determined M40 indices of $77.80 \%, 70.80 \%, 78.20 \%$ and $64.16 \%$ determined for $B V 1, B V 2$, AA and $C E$ respectively by 0.18 units, 6.32 units, -0.65 units, and 27.89 units respectively. Thus, the best M40 index predicted was determined for BV1 blend with $0.97 \mathrm{G}$-value and 18 hours coking time with only a small allowable deviation of 0.18 units. The CRE formula has therefore been shown to be valid to predict M40 index of coke produced from coal blends with G-value of about 0.97 and carbonized at a moderate coking time of 18 hours. It has also been shown that the coking conditions that produce the best M40 index also produced the best M10 index.
\end{abstract}

Keywords: coal, blends, coking, micum, indices 


\section{INTRODUCTION}

The chemical composition of a coal depends on the proportions of the different chemical components present in the parent plant debris, the nature and the extent of the changes which these components have been subjected to since their deposition and the nature and quantity of the inorganic matter present [1]. The rank of a coal is the degree of change of chemical composition of the coal within the series of fossil fuel from the least mature peat to the most mature anthracite. When a bituminous coal is subjected to high temperatures, it undergoes some changes which among others include decomposition into a number of complex compounds, the evolution of various gaseous and condensing substances, conversion into plastic mass at specified temperatures as a result of melting of its bitumen constituents and conversion of the formed plastic mass into non-plastic due to further molecular decomposition of the organic mass [1,2].

This process of thermal decomposition of bituminous coal results in the formation of coke, a solid residue with sufficient mechanical strength to withstand abrasive forces when a column of smelted charge descends in a blast furnace. The coke mechanical strength are indicated as micum 10 (M10) and micum 40 (M40) which are indices of resistance to abrasion and fragmentation, respectively.

Dilatometers and plastometers are commonly used to study coals plastic properties. On the basis of Ruhr dilatometric parameters, Simonis developed a mathematical formula to determine the G-value coking capacity that indicates the cokeability of a coal[3,4].

The Simonis formula is :

$G=\frac{E+V}{2} x \frac{c+d}{V x c+E x d}$

where

$(E)=$ Softening temperature $(E)$

$(\mathrm{V})=$ Temperature of maximum dilatation $(\mathrm{V})$

(c) = Maximum contraction \%(c)

(d) $=$ maximum dilatation $\%(\mathrm{~d})$

Following extensive carbonization tests, the UK Coke Research Establishment (CRE) developed an empirical formula to predict the micum 40 (M40) strength of coke[3]. The formula is :

$M 40=103.9+24.8 G-1.196 \times 10^{-6} V^{5}+2.57 \frac{V^{2}}{T}-\frac{88 V}{T}$

Where

(G) = G-value coking capacity of the coal charge

$(\mathrm{V})=$ Volatile matter content (daf)

$(\mathrm{T})=$ Time in hours of carbonization (to center temperature of

$900^{\circ} \mathrm{C}$ ) in an oven of average width of $450 \mathrm{~mm}$. 
The aim of this study is to compare the micum 40 indices obtained for coke produced from coals imported for the Ajaokuta Steel Plant from Australia, Poland and United States of America with the M40 indices obtained by the CRE formula. Since the CRE formula was obtained following 170 carbonization tests in the same type of $250 \mathrm{~kg}$ coke oven [3] used for the imported coals, deductions from the comparison may provide useful technical factors for successful industrial scale cokemaking operations.

\section{MATERIALS AND METHODS}

\section{MATERIALS}

Samples of Bellview 1, Bellview 2, Agro-Allied and Carbon Energy coals sourced from Poland, Australia and United States of America, respectively.

\section{METHODS}

\section{Proximate Analysis}

Proximate analysis of coal involves the determination of moisture, volatile matter, ash and fixed carbon contents.

\section{Moisture Content}

The crucible was preheated at a temperature of $110^{\circ} \mathrm{C}$ for 1 hour. $1 \mathrm{~g}$ of coal ground to pass 250 microns was heated in the crucible at $110^{\circ} \mathrm{C}$ for 1 hour. The loss in weight accounts for the moisture content.

\section{Volatile Matter (VM)}

The silica crucible was pre-heated in the muffle furnace for 7 minutes at $900^{\circ} \mathrm{C}$ and cooled. $1 \mathrm{~g}$ of sample ground to pass 250 microns was then placed in the crucible and heated in the muffle furnace for 7 minutes at $900^{\circ} \mathrm{C}$. The loss in weight accounts for the volatile matter of the coal sample.

\section{Ash Content}

The silica crucible was pre-heated in a muffle furnace at $825^{\circ} \mathrm{C}$ for 1 hour. It was then cooled and weighed. $1 \mathrm{~g}$ of sample ground to pass 250 microns was then placed in the crucible and heated in the muffle furnace at $825^{\circ} \mathrm{C}$ for 1 hour with the lid on. It was then cooled in the desiccators and weighed. The incombustible residue constitutes the ash content.

\section{Fixed Carbon}

Fixed carbon of the coals were determined by calculation with the relation:

$\%$ Fixed carbon $=100-\%$ moisture $-\%$ Ash $-\%$ VM 


\section{Ruhr Dilatometry}

In Ruhr dilatometry, the variation in the length of a column of coal during heating is measured. The coal sample ground to pass 250 micron sieve was compacted into a pencil form. The pencil of coal was then placed in a metal tube and a piston rod was inserted into the tube to rest on piston's top. The other end of the piston rod was attached to a rotating barrel to record the vertical movement of the piston. On heating, the column of coal softened and contracted in length due to the plastic deformation under the action of piston. When the coal softened, bubbles of gas were evolved causing the coal column to swell up. The dilatation percent of the coal indicates its coking power.

\section{Determination of Micum Strength}

The coal samples were carbonized by normal charging in a $250-\mathrm{kg}$ capacity coke oven. Typical normal charging carbonization conditions used were:

Flue temperature $-1020^{\circ} \mathrm{C}$

Bulk density $-830 \mathrm{~kg} / \mathrm{m}^{3}$

Carbonization period -15 hours

Charge temperature $-1250^{\circ} \mathrm{C}$

The determination of micum indices involves coke stabilization, coke screening and micum drum test. In coke stabilization, the coke yield was dropped from a height of $5 \mathrm{~m}$ into a metal receiver once. The stabilized coke was then screened through vibrating round hole screens of sizes $<10,10-20,20-40,40-60,60-80$ and $>80 \mathrm{~mm}$. For micum drum test, $50 \mathrm{~kg}$ of the screened coke was subjected to $25 \mathrm{rev} / \mathrm{mm}$ for $4 \mathrm{~min}$ in a steel drum and screened again. The micum 10 (M10) was determined as the percentage of the coke residue below 10mm sieve size and micum 40 (M40) the percentage of the coke residue above $40 \mathrm{~mm}$ sieve size. The calculation of the micum indices for the Agro-Allied coal blend is as follows:

(i) Determination of screen distribution analysis (Table 3)

(ii) Determination of the percentages of coke retained on sieve sizes $+40 \mathrm{~mm}$ (Table 4).

(iii) Calculation of the proportion of each sieve size range in the $50 \mathrm{~kg}$ micum drum sample (Table 5).

\section{RESULTS AND DISCUSSION}

\section{RESULTS}

The results of the analyses are presented in Tables 1 to 5 . 
Table 1: Proximate Analysis

\begin{tabular}{|l|l|l|l|l|l|}
\hline S/No & Parameters \% & BV1 & BV2 & AA & CE \\
\hline 1. & Moisture (ad) & 1.5 & 0.8 & 0.87 & 1.47 \\
\hline 2. & Ash $(\mathrm{db})$ & 5.8 & 6.1 & 9.72 & 2.66 \\
\hline 3. & Volatile matter (daf) (V) & 31.8 & 31.3 & 30.2 & 21.90 \\
\hline 4. & Fixed carbon (db) & 61.0 & 61.8 & 63.01 & 75.28 \\
\hline
\end{tabular}

Note: ad-as determined, daf -dried ash free

Table 2: Ruhr dilatometric parameters and coking parameters

\begin{tabular}{|c|c|c|c|c|c|}
\hline S/No & Parameters \% & BV1 & BV2 & $\mathbf{A A}$ & CE \\
\hline 1. & Softening temp. ${ }^{0} \mathrm{c}$ & 406 & 404 & 395 & 408 \\
\hline 2. & Maximum contraction $\%$ & 26 & 24 & 22 & 28 \\
\hline 3. & Maximum dilatation $\%$ & 10 & -7 & -8 & 40 \\
\hline 4. & Maximum contraction temp. ${ }^{0 \mathrm{C}}$ & 440 & 439 & 424 & 437 \\
\hline 5. & Maximum dilatation temp $\mathrm{c}$ & 463 & 462 & 440 & 482 \\
\hline 6. & G-value $(\mathrm{G})$ & 0.97 & 0.93 & 0.94 & 1.01 \\
\hline 7. & Micum 10 (M10) & 11.40 & 15.40 & 15.40 & 25.00 \\
\hline 8. & Micum to (M40) & 77.80 & 70.80 & 78.20 & 64.16 \\
\hline 9. & Duration of carbonization (hrs) (T) & 18 & 17 & 16 & 22.5 \\
\hline 10. & Calculated M40 & 77.98 & 77.12 & 77.55 & 92.05 \\
\hline 11. & Deviation & 0.18 & 6.32 & -0.65 & 27.89 \\
\hline 12 & Percentage deviation & 0.23 & 8.93 & 0.83 & 43.47 \\
\hline
\end{tabular}

Table 3: Screen distribution of Agro-Allied Coke

\begin{tabular}{|l|l|}
\hline Sieve $(\mathbf{m m})$ & Weight $(\mathbf{k g})$ \\
\hline-10 & 13.85 \\
$+10-20$ & 2.45 \\
$+20-40$ & 5.35 \\
$+40-60$ & 20.17 \\
$+60-80$ & 47.65 \\
+80 & 64.82 \\
\hline Total & 154.29 \\
\hline
\end{tabular}

Table 4: Percentages of Coke retained $+40 \mathrm{~mm}$ sieve ranges

\begin{tabular}{|l|c|c|}
\hline \multicolumn{1}{|c|}{ Sieve (mm) } & Weight $\mathbf{( k g )}$ & Wt \% \\
\hline$+40-60$ & 20.17 & 15.21 \\
$+60-80$ & 47.65 & 35.92 \\
+80 & 64.82 & 48.87 \\
\hline Total & 132.64 & $100 \%$ \\
\hline
\end{tabular}


Table 5: Proportions of $+40 \mathrm{~mm}$ sieve range in micum drum sample

\begin{tabular}{|c|c|c|}
\hline Sieve (mm) & Wt (\%) & Wt (kg) \\
\hline$+40-60$ & 15.21 & 7.60 \\
$+60-80$ & 35.92 & 17.96 \\
+80 & 48.87 & 24.44 \\
\hline
\end{tabular}

\section{DISCUSSION}

The G-value determined for coal blends BV1, BV2, AA and CE are 0.97, 0.93, 0.94 and 1.01, respectively. The G-value of 0.97 and 1.01 for blends BV1 and CE, respectively, fall within the range of 0.95 to 1.15 indicated by Simonis for most medium and strongly coking coals [3]. The G-value of 0.97 was also determined for a German coal blend that produced coke of micum 10 and micum 40 of $7 \%$ and $78.1 \%$, respectively. The micum 40 of $77.80 \%$ determined for blend BV1 is observed to be only 0.4 units lower, while its micum 10 of $11.40 \%$ is only 4.4 units above that of coke from the German blend [5]. The G-value thus gives a fairly reliable indication of coke strength. However, the poorer micum 40 of $64.16 \%$ for blend CE when compared with 0.97 shows that micum 40 strength does not increase in direct proportion to G-value.

For micum 10, the best abrasion resistance was obtained for the BV1 coal blend and the worst micum 10 value of $25 \%$ was obtained for the highest G-value of 1.01 . These results also indicate that the M10 index does not improves in direct proportion to the G-value. It is also noted that the micum 10 indices for blends BV2 and AA with G-values 0.93 and 0.94 respectively, which falls below the Simonis range $(0.95$ to 1.15$)$ produced coke with better M10 indices than coal blend CE with the higher G-value. These results suggest that the G-value coking capacity parameter gives a fairly accurate indication of coke strength not only for coals within the Simonis range but also below.

For German cokemaking practice, a carbonization period of 18 to 24 hours is specified for cokemaking in $250 \mathrm{~kg}$ capacity coke ovens [6]. The carbonization periods used were 18 hours, 17 hours, 16 hours and 22.5 hours for blends BV1, BV2, AA and CE, respectively. The blend AA with the lowest coking period of 16 hours gave the best M40 index of $78.20 \%$, while the blend CE with the longest coking period of 22.5 hours gave the worst M40 index of $64.16 \%$. The very high coking period for blend CE may account for the low M40 index of its coke. It is also noted that the best M10 index of $11.40 \%$ was obtained for the BV1 coke with 18 hours coking time, while the worst M10 index of 25\% was obtained for the CE coke carbonized for 22.5 hours. Both BV2 and AA coke produced at 17 hours and 16 hours, respectively, have the same M10 index, while the M40 index of the latter exceeds the former by 7.40 units. Coking durations which are as low as 14 hours had been used for cokemaking in India [7]. These results suggest that high coking period improves the M10 index, while low coking period promotes the M40 
index. Thus, moderate coking period of say 18 to 19 hours may be the most appropriate to produce high-grade coke with good resistance to fragmentation and abrasion.

The volatile matter (daf) of $31.80 \%, 31.30 \%, 30.20 \%$ and $21.90 \%$ were determined for blends BV1, BV2, AA and CE, respectively. Thus, blends BV1, BV2 and AA are high volatile, while $\mathrm{CE}$ is low volatile [8]. The volatiles for the first three blends thus exceed the $24.01 \%$ for a medium volatile Indian coking coal [7] but are lower than the volatiles of $39.4 \%$ to $41.8 \%$ for coals carbonized to produce high grade coke in Japan [9]. Coals with volatiles of $17-22 \%$, which include the volatile of $21.70 \%$ for $\mathrm{CE}$ blend have also been included in blends for cokemaking in France [7]. These results suggest that the volatile contents of the four blends are such that they may produce metallurgical grade coke.

From the analysis results, the best M40 index of 78.20\% was determined for blend AA with $30.22 \%$ volatile, while higher and lower volatiles gave poor M40 index. The best M10 index of $11.40 \%$ was obtained for blend BV1 with higher volatile of $31.8 \%$. Thus, blends with moderately high volatiles may be the most appropriate to produce high-grade coke. This deduction agrees with the specification that coals for cokemaking at Ajaokuta have volatiles ranging from $27.7 \%$ to $30.30 \%$ [10].

The CRE formula shows that the M40 index increases with increasing G-value between 0.89 to 1.13 , which includes the G-values for all the blends carbonized (i.e. 0.93 to 1.01). The CRE formula is thus applicable to these coals. The fixed carbon content tends to increase with decreasing value of volatile between 31.80 and $30.22 \%$. The CRE M40 predicted is observed to generally decrease with carbonization time. Negative values of $11,-13.9,-19.5,-30.9$ units were calculated for the $18 \mathrm{hrs}, 17 \mathrm{hrs}, 16 \mathrm{hrs}$ and $22.5 \mathrm{hrs}$ carbonization period in the terms containing T. The M40 index thus generally decreases at too low coking period (e.g. 16hours) and too high coking period (e.g. 22.5hours). Thus, moderate coking period of about 18 hours may be the most appropriate. The coking period of 18 hours falls within the range of 13.9 to 19.5 hours specified by CRE to obtain valid CRE prediction of M40 [3]. For a valid CRE formula prediction, the volatile matter content range is $19 \%$ to $41 \%$, which includes all the coal blends considered.

The deviation of calculated CRE M40 indices from the experimentally determined indices are 0.18units, 6.32units, -0.65 units and 27.89 units (that is, $0.23 \% 8.93 \% 0.83 \%$, and $43.47 \%$ in percentages), respectively. The deviation fall below the 3.2units determined for blends carbonized at CRE except for BV2 and CE blends [3]. It is observed that these unacceptable deviations occur at the lowest G-value of 0.93 and the highest G-value of 1.01, while the least deviation occur at G-value of 0.97. These results further confirm the BV1 blend as the best blend to produce the highest-grade coke. These results also show that the coking conditions that give the best predicted M40 also produced the best M10 index determined experimentally. 


\section{CONCLUSION}

The G-value, the volatile content and the coking periods of the blends carbonized agree with the range of values of these parameters specified for coals to which the CRE M40 index may apply, except for CE blend which deviate in coking time. The best M40 index was predicted for blend BV1 with $0.97 \mathrm{G}$-value and a moderate coking time of 18hours. Furthermore, the least deviation of 0.18 units from the actual M40 index was determined for BV1. The CRE M40 formula is thus applicable to predict the M40 index of coals to produce coke at Ajaokuta using the bench scale parameters of G-value and volatile content.

\section{REFERENCES}

[1] Krivandin, V. and Markov, B., 1980, Metallurgical Furnaces, $1^{\text {st }}$ edn., Mir Publishers, Moscow.

[2] Moitra, A.K., Banerjee, N.G., Shrinkhande, K.Y., Sing, K., Raja, K. and Banerjee, S., 1972, "Studies on coal carbonization in India", Central Fuel Research Institute (FRI), Publication, pp. 17-23, 35-36.

[3] Gibson, J., 1972, "Dilatometry and the Prediction of coke quality". Yearbook of Coke Oven Managers, UK. pp. 182-201.

[4] Afonja, A.A., 1991, New Techniques of low coking coal utilization in the blast furnace, In: The Seminar on the Potential of Nigeria Coals for Industries, Lagos.

[5] Weskamp W., Rhode, W., Stewen, W., and Habermehl, T., 1987, "Greater coke strength through reactive additives to coking blends", $1^{\text {st }}$ International Cokemaking Congress, Essen, Section III.

[6] National Metallurgical Development Centre (NMDC), Report of training at Deutsche Montane Technologies, Germany.

[7] Prasad, H.N., Rao, P.V.T., Poddar, N.N. and Chaterjee, A., 1992, "Selection of coals for cokemaking by classical top charging and stamp charging". $2^{\text {nd }}$ international cokemaking congress, London, pp 231-235.

[8] Garin, J., Pol, F. and Poulet, Ph., 1987, "Coal selection and blending practice at the USINOR Coke oven plant". $1^{\text {st }}$ International Cokemaking Congress, supplementary volume pp., Section III. 2.

[9] Katsuhiko, O., Akira, K., Mitsumas, J., Seiji, N. And Kan, A., 1987, "Evaluation of coking Coal", $1{ }^{\text {st }}$ International Cokemaking Congress, preprints Vol. 1, Essen, Section E. 1 .

[10] Raw Materials specifications, 1994, for Federal Government Steel Companies, $1^{\text {st }}$ edn., pp. 6. 